\title{
Cultura no plural: reflexões e interpretações em (des)construção
}

\author{
Cultura en el plural: reflexiones e interpretaciones en (de)construcción
}

\section{Culture in the plural: reflections and interpretations in (de)construction}

\author{
Camila Oliveira Fonseca ${ }^{1}$
}

\begin{abstract}
Resumo
Em consonância com as expansões interpretativas ou expansões de perspectivas propostas por Monte Mór (2018), o presente trabalho busca refletir sobre o(s) sentido(s) de cultura a fim de desafiar a lógica dominante que sustenta e regula os processos culturais que determinam as representações sobre nós mesmos e sobre a realidade. A partir de uma perspectiva decolonial, este artigo visa a possibilitar interpretações que acompanhem a pluralidade, a diversidade e a heterogeneidade de formas de pensar e de agir emergentes de localidades múltiplas e que impulsionam novos paradigmas e novos modos de (re)construir a realidade, para que nossas práticas (sociais, acadêmicas, educacionais) não se façam alheias à responsabilidade social, cultural, intelectual e política que ampara a práxis questionadora aqui pretendida. Para tanto, o presente artigo abre espaços de diálogo com teorias diversas, sem delimitar o escopo interpretativo do texto, numa tentativa de abandonar o casulo das certezas relativas e de possibilitar novas interpretações que transcendam as fronteiras disciplinares.
\end{abstract}

Palavras-Chave: Cultura; espaço semiótico; diferença; desconforto; pluriversalidade.

\section{Resumen}

En línea con las expansiones interpretativas o expansiones de perspectivas propuestas por Monte Mór (2018), el presente trabajo busca reflexionar sobre los sentidos de cultura para desafiar la lógica dominante que sostiene y regula los procesos culturales que determinan las representaciones sobre nosotros mismos y sobre la realidad. Desde una perspectiva decolonial, este artículo tiene como objetivo posibilitar interpretaciones que acompañen la pluralidad, diversidad y heterogeneidad de las formas de pensar y actuar emergentes de múltiplas ubicaciones y que impulsan nuevos paradigmas y nuevas formas de (re)construir la realidad, para que nuestras prácticas (sociales, académicas, educacionales) no ignoren la responsabilidad social, cultural, intelectual y política que respalda la praxis cuestionadora aquí deseada. Con este fin, este artículo abre espacios para el diálogo con diversas teorías, sin delimitar el alcance interpretativo del texto, en un intento de abandonar el capullo de las certezas relativas y de permitir nuevas interpretaciones que trasciendan las fronteras disciplinarias.

Palabras Clave: Cultura; espacio semiótico; diferencia; incomodidad; pluriversalidad.

\begin{abstract}
In line with the interpretive expansions or expansions of perspectives proposed by Monte Mór (2018), this paper seeks to reflect on the sense(s) of culture in order to challenge the dominant logic that sustains and regulates the cultural processes that determine representations about ourselves and about reality. From a decolonial perspective, this article aims to enable interpretations that accompany the plurality, diversity and heterogeneity of ways of thinking and acting which emerge from multiple locations and that propel new paradigms and new ways of (re)building reality, so that our practices (social, academic, educational) do not ignore the social, cultural, intellectual and political responsibility that supports the questioning praxis here intended. To this end, this article opens spaces for dialogue with diverse theories, without delimiting the interpretative scope of the text, in an attempt
\end{abstract}

\footnotetext{
${ }^{1}$ Doutoranda em Estudos Linguísticos, na Área de Linguística Aplicada, pela Universidade Federal de Minas Gerais, Belo Horizonte, Minas Gerais, Brasil e Mestre em Estudos Linguísticos, na Área de Linguística Aplicada, pela Universidade Federal do Espírito Santo, Vitória, Espírito Santo, Brasil; contato.camilafonseca@ hotmail.com
} 
to abandon the cocoon of relative certainties and to enable new interpretations that transcend disciplinary boundaries.

Keywords: Culture; semiotic space; difference; discomfort; pluriversality.

\section{Introdução}

Somos, enfim, o que fazemos para transformar o que somos. A identidade não é uma peça de museu, quietinha na vitrine, mas a sempre assombrosa síntese das contradições nossas de cada dia.

Galeano, Eduardo. Celebração das contradições/2. Em 'O livro dos abraços'.

O movimento crítico almejado ao longo do presente artigo foi o de pensar a cultura a partir da desconstrução e/ou desestabilização do signo 'cultura' e dos sistemas de significação que visam a naturalizá-lo de acordo com seus interesses discursivo-político-ideológicos. Conforme afirma Bakhtin, o signo é um fenômeno ideológico por excelência (2006) e, por meio dele, portanto, as criações ideológicas são materializadas e naturalizadas.

Tal deslocamento nos permitiu pensar a cultura para além de conceitos generalizantes, num exercício dialógico de expansão de perspectivas (MONTE MÓR, 2018) que, em vez de focalizar uma resposta única, ou um determinado entendimento de cultura, contribuiu para que nos entendêssemos como sujeitos sócio-históricos que, em constante formação/construção, produzem e negociam sentidos e, assim, promovem encontros e confrontos culturais que resultam em novas possibilidades de interpretação de suas próprias identidades, bem como dos possíveis sentidos de cultura.

Para tornar tal empreitada possível, buscamos estabelecer diálogo em vários espaços e com teorias diversas, sem delimitar o escopo interpretativo do texto, numa tentativa de desterritorializar (GARCIA-CANCLINI, 2011) as nossas próprias reflexões sobre cultura e de possibilitar novas interpretações que transcendam as fronteiras disciplinares.

Na primeira parte do texto, buscamos melhor compreender a narrativa de cultura como Estado-nação, visando aprofundamento nas narrativas hegemônicas que nos atravessam, no sentido de possibilitar o deslocamento aqui pretendido. Em seguida, falamos de cultura como espaço semiótico, no intuito de promover diálogo e negociação de sentidos. Na terceira seção, focalizamos a diferença como elemento fundamental na construção de identidades culturais, destacando, ainda, o desconforto que se coloca como desafio nos processos culturais em que a diferença é legitimada. Seguidamente, observamos como o pensamento decolonial contribui 
com o exercício de deslocamento, nos permitindo pensar a interculturalidade como forma de transpor os sentidos estanques que limitam as nossas experiências. Encerramos o texto com algumas breves considerações que, esperamos, ajudem a multiplicar as possibilidades de interpretação do que aqui entendemos como cultura.

\section{Afastando a narrativa de Estado-nação: preparando o (des)território}

Para que pudéssemos desterritorializar nossos pensamentos naturalizados sobre cultura, precisaríamos, antes, compreender como tais pensamentos foram produzidos, normalizados (e normatizados). A ideia de Estado-nação, nascida na Europa ao final do séc. XVIII e início do séc. XIX e que se projetou para o mundo como referência civilizacional e como modelo a ser seguido, tornou-se poderosa fonte de significados para as identidades culturais modernas (HALL, 2006). Esses significados são construídos e reforçados por meio da narrativa de nação, que

fornece uma série de estórias, imagens, panoramas, cenários, eventos históricos, símbolos e rituais nacionais que simbolizam ou representam as experiências partilhadas, as perdas, os triunfos e desastres que dão sentido à nação. Ela dá significado e importância à nossa monótona existência, conectando nossas vidas cotidianas com um destino nacional que preexiste a nós e continua existindo após nossa morte (HALL, 2006, p. 52).

Dessa forma, a ideologia dominante legitima como senso comum aquilo que fora construído a partir da narrativa de Estado-nação, e os valores da cultura dominante são transmitidos por meio do que Boler e Zembylas (2003) chamam de 'história popular' - narrativa reducionista que despreza a complexidade com que significados e identidades são produzidos, promovendo uma falsa sensação de conforto e segurança - e que reforça suas crenças por meio de discursos validados por instituições como a mídia de massa e a escola, que ditam "padrões de comportamento recorrentes, valorizados e estáveis" (HUNTINGTON, 1965, p. 394). Assim, somos levados a nos identificar com a imagem da cultura nacional, a despeito de nossas diferenças e contradições. Por essa razão, ao falarmos de identidade cultural, muitas vezes a reduzimos àquilo que se nos assemelha; identidade como conformidade, homogeneidade, similitude.

A partir desse entendimento de identidade, a identificação e a semelhança tornam-se desejáveis, pois o senso de pertencimento nos permite viver em sociedade sem que (aparentemente) sejamos alvos de preconceito ou discriminação por determos características mais ou menos equivalentes aos demais membros do grupo e, por essa razão, somos por eles 
aceitos e reconhecidos como 'iguais'. E, por sermos reconhecidos como membros de um Estado-nação, temos por ele garantidos (e regulados) os nossos direitos civis e políticos.

Segundo Arendt (1998), tal processo de homogeneização cultural levou os indivíduos a adotarem determinados comportamentos para que pudessem "caber" no modelo social da modernidade, o que resultou no apagamento (conformismo) de quaisquer ações espontâneas que pudessem divergir das normas sociais então almejadas: "o comportamento substituiu a ação como o principal modo de relacionamento humano"2 (ARENDT, 1998, p. 41). Contudo, ao regular o comportamento dos indivíduos, a narrativa de 'família nacional' (HALL, 2006, p. 59), enquanto estrutura de poder cultural, esforça-se por suprimir as diferenças imanentes à própria condição humana, tentando “'costurar' as diferenças numa única identidade” (HALL, 2006, p. 65, grifos do autor). Ainda, segundo Hall, “as identidades nacionais não subordinam todas as outras formas de diferença e não estão livres do jogo de poder, de divisões e contradições internas [...] e de diferenças sobrepostas" (p. 65). O autor destaca o próprio fenômeno da globalização como processo que atravessa as fronteiras nacionais, possibilitando a formação de novas identidades de constituição híbrida, "desvinculadas de tempos, lugares, histórias e tradições específicos" (HALL, 2006, p. 73). Assim, as identidades extrapolam para além da narrativa dominante, e revelam seu caráter plural e movente.

A respeito do que Arendt (1958, p. 230) prefere chamar de 'tragédia do Estado-nação', cabe ainda destacar as consequências nefastas desse processo de dominação política, cultural e ideológica para aqueles que foram privados de nacionalidade por não caberem na narrativa totalitária de nação. Consequências que vão desde o extermínio ou a subjugação de povos ao longo da história, e que continuam a se multiplicar no contexto atual das migrações, na forma de 'racismo cultural' (HALL, 2006) e exclusão, negando aos indivíduos o direito à cidadania:

\begin{abstract}
a primeira perda que os destituídos de direitos sofreram foi a perda de seus lares, e isso significou a perda de toda a textura social na qual eles nasceram e na qual eles estabeleceram para si um lugar distinto no mundo. Essa calamidade está longe de ser sem precedentes; na longa memória da história, migrações forçadas de indivíduos ou grupos inteiros de pessoas por razões políticas ou econômicas se parecem a ocorrências cotidianas. O que é sem precedentes não é a perda de um lar, mas a impossibilidade de encontrar um novo. De repente, não havia lugar na terra onde os migrantes pudessem passar sem as mais severas restrições, nenhum país onde seriam assimilados, nenhum território onde eles pudessem fundar uma nova comunidade (ARENDT, 1958, p. 293).
\end{abstract}

Em oposição à ideia excludente e homogeneizante de Estado-nação, Arendt (apud DEBARBIEUX, 2017) reforça que comunidades são formadas por uma pluralidade de

\footnotetext{
2 Todas as traduções presentes no texto são de responsabilidade desta autora.
} 
indivíduos que representam uma multiplicidade de pontos de vista e de posições relativas que precisam ser compartilhadas e debatidas para que emerjam novas identificações e novas formas de ser e de agir no mundo.

Portanto, ainda que habitemos um mesmo mundo material, cada um de nós o percebe de maneira distinta, segundo a pluralidade de nossas vivências, experiências, pontos de vista e, ainda, segundo a posição que ocupamos e como nos entendemos no mundo. E, ao reconhecermos a parcialidade e a relatividade de nossas próprias interpretações e identidades, entendemos que a diferença não constitui ameaça, mas nos permite expandir nossa própria existência quando, em contato com outros indivíduos e outras identidades, nos abrimos ao diálogo e à construção de novos sentidos e novas interpretações. Como afirma Arendt (1978, apud DEBARBIEUX, 2017, p. 355), "nada do que é, na medida em que aparenta ser, existe no singular; tudo o que existe é para ser percebido por alguém. [...] Pluralidade é a lei da terra".

E, na medida em que elegemos a diferença, em detrimento da semelhança, como elemento fundamental na formação das identidades culturais, deslocamos a visão estática de cultura imaginada para reconhecermos a pluralidade e a dialética das relações que nos permitem pensar a cultura de forma menos condicionada e mais dialógica. E é o que pretendemos fazer a seguir.

\section{Reflexões sobre cultura como espaço semiótico}

Ao pensar em cultura(s) de forma desterritorializada (não condicionada a uma única interpretação) e, ao mesmo tempo, localizada (dadas as contingências das nossas próprias interpretações e dos construtos que as sustentam), começamos a percebê-la "no 'terceiro' espaço das relações complexas e desconfortáveis nas quais identidades, poder e ideias são negociados" (ANDREOTTI; MENEZES DE SOUZA, 2008, p. 29, grifo dos autores). Ou seja, percebemos cultura como sendo socialmente construída nos espaços de engajamento (CORNWALL, 2002) ou de negociação social e cultural. É importante destacar que o termo espaço não representa o lugar material, mas "o limiar em que o jogo de relações se orienta pelos mecanismos culturais de multiplicação dos contatos, das línguas, linguagens e processos de comunicação cultural" (MACHADO, 2015, p. 113). Para a autora, "a cultura assim focalizada mostra-se um espaço de encontros, confrontos e, sobretudo, de fronteiras entre superfícies e linguagens culturais" (MACHADO, 2015, p. 113). As fronteiras não se referem a mera delimitação geográfica, mas caracterizam o próprio dualismo dos encontros e/ou confrontos que, muitas vezes, tensionam as relações estabelecidas no contato entre o próprio e o alheio, ou seja, entre aquilo que identificamos como "nossa" cultura e como a "cultura do outro". 
Esse espaço de encontros e confrontos tem a cultura como força motriz, e embora a noção de cultura ainda resista em carregar sentidos mais ou menos estabilizados (sistemas culturais, mecanismos culturais, linguagens culturais), concordamos ser impossível moldá-la a um único significado, ou a um único território, como pudemos observar anteriormente. $\mathrm{O}$ espaço de construção e negociação de sentidos, ou o espaço semiótico (cf. MACHADO, 2015), aqui representa o movimento, o deslocamento, a heterogeneidade, as continuidades e descontinuidades.

Até mesmo aquilo que nos é transmitido como herança é também transformado e ressignificado quando interagimos com o mundo. A partir do nosso lócus de enunciação, construímos novos sentidos e relações que diluem a noção estática e determinista de cultura e a convertem em um movimento de descentramento e desdobramento, em que ela se refaz continuamente em determinado espaço-tempo. Como afirma Maher (2007, p. 89), "as culturas propõem sistemas de significação, mas não são camisas de força. A cultura não é só pensada, mas também vivida. As significações são continuamente reavaliadas e transformadas pela ação humana".

Nesse sentido, a cultura como espaço semiótico nos aproxima da visão dialógica de Bakhtin (2002), em que as forças centrípeta e centrífuga agem sobre o contato cultural, sendo a primeira de natureza centralizadora e estabilizadora, e, a segunda, ao contrário, tenta minar essa força centralizadora, direcionando para o movimento e a instabilidade. Essa tensão entre forças constitui o espaço imprevisível das relações dialógicas, em que a própria cultura (bem como os indivíduos, as identidades, a língua/linguagem, o conhecimento) se constitui e se transforma continuamente.

As forças centrípeta e centrífuga promovem embates culturais que ocorrem dentro da dinâmica das relações de poder, ou seja, trata-se de um embate ideológico que sugere direções espaciais distintas e antagônicas. As relações de poder desiguais produzem e sustentam dicotomias como as de alta cultura e baixa cultura, civilização e barbárie, etc. Kubota (2004) defende que essas dicotomias são discursivamente construídas, e podem, portanto, ser questionadas e problematizadas no diálogo intercultural. Para tanto, entendemos que toda interação e/ou negociação cultural deve ser acompanhada de reflexão crítica que possibilite o desvelamento das injustiças. Para Canagarajah (2006, p. 5), “o pensamento crítico não é uma disposição humana abstrata ou universal, mas mediada pela cultura".

Assim, entendemos que o desenvolvimento da criticidade e a reconfiguração das relações de poder podem ser almejados no diálogo das relações culturais que estabelecemos cotidianamente. E, visando a fomentar reflexões críticas que venham a dialogar com as 
interpretações tecidas até aqui, e, ainda, na esperança de que possam se juntar a outras reflexões para além desse texto, buscaremos agora expandir nossas perspectivas, na tentativa de privilegiar a diferença como peça chave dos pensamentos sobre cultura.

\section{A diferença e a pedagogia do desconforto}

Boler eZembylas (2003) propõem que nos desloquemos de nossas zonas de conforto para que possamos nos engajar a um pensamento crítico que questione as nossas próprias visões de mundo. Para os autores, zonas de conforto compreendem "os espaços culturais e emocionais que ocupamos menos por escolha e mais em virtude da dominação hegemônica” (BOLER; ZEMBYLAS, 2003, p. 108), já que ela se dá no cotidiano das práticas sociais: “a zona de conforto reflete investimentos emocionais que, de um modo geral, permanecem sem exame porque foram tecidos no cotidiano do que é considerado senso comum" (BOLER; ZEMBYLAS, 2003, p. 108).

Destarte, o exercício do pensamento crítico requer vigilância epistêmica, requer que reconheçamos que nossos próprios valores podem estar (e, não raro, estão) respaldados na lógica dominante. Por essa razão, Boler e Zembylas (2003) afirmam que o engajamento crítico exige um grande trabalho e/ou esforço emocional (emotional labor, p. 108), pois, conforme defendem os autores, "ninguém escapa à hegemonia" (p. 112). Sejamos nós membros da cultura dominante (e reconhecidos pela narrativa da nação) ou das culturas marginalizadas (excluídos ou subalternizados pela narrativa de Estado-nação), todos estamos sujeitos às estruturas de poder (ou à grande parte delas) que orientam os nossos comportamentos e as nossas ações, como a família, a religião, a escola, a mídia de massa, bem como o próprio Estado. Somos, portanto, conscientemente ou não, atravessados por estruturas e construtos hegemônicos reguladores, e desprender-se delas/deles aparenta ser tarefa bastante laboriosa, todavia, extremamente importante para que possamos deixar o casulo das nossas certezas relativas e assim passarmos a acolher a complexidade e a diferença como formas de fomentar outras histórias e outras narrativas que por hora seguem suprimidas e oprimidas pelos ideais reguladores da ideologia dominante. E, claro, como forma de motivar outras versões e interpretações acerca dos sentidos de cultura.

Para designar as construções que se dão na articulação das diferenças culturais, Bhabha (1998) usa o termo in-between, traduzido para o português como 'entre-lugar', como posição que permite que sejam vislumbrados "outros de nós mesmos" (BHABHA, 1998, p. 69). Para Bhabha, o entre-lugar representa o hibridismo, a sobreposição e a negociação de valores culturais que revelam a contingência das histórias nacionais e trazem à tona "histórias nacionais 
antinacionalistas" (p. 69). O termo 'entre-lugar' fora formulado anteriormente pelo escritor e crítico literário brasileiro Silviano Santiago no início da década de 1970, quando, a partir de um córpus teórico fundamentado em Foucault e Derrida, analisa a produção literária latinoamericana na obra "Uma literatura nos trópicos: ensaios sobre dependência cultural" (19782000). No ensaio "O entre-lugar do discurso latino-americano", Santiago configura o termo 'entre-lugar' como forma de resposta estratégica ao pensamento colonizador/dominante. Segundo o autor, "na álgebra do conquistador, a unidade é a única medida que conta" (SANTIAGO, 2000, p. 14). Assim, ao imprimir um movimento de descentramento ou de desestabilização da unidade hegemônica, encontramos formas alternativas de agir no mundo, engendrando "a sociedade dos mestiços, cuja principal característica é o fato de que a noção de unidade sofre reviravolta, é contaminada em favor de uma mistura sutil e complexa" (p. 15). Essa mistura desestabiliza e desconstrói a noção de unidade e de pureza, e representa um posicionamento crítico contra-hegemônico que reconhece e legitima a diferença como lócus de enunciação do 'entre-lugar', revelando a nação fragmentada dentro dela própria, articulando a heterogeneidade daqueles que dela fazem parte (BHABHA, 1998).

Quando trazemos a reflexão acima para o espaço das relações sociais, temos como desafio desestabilizar comportamentos agudamente naturalizados pela lógica hegemônica. Boler e Zembylas (2003) apresentam três exemplos comuns de concepções bastante simplistas e redutoras no que tange à forma com que nos relacionamos com a diferença:

A primeira, chamada de modelo da celebração ou da tolerância, inclui discursos do tipo "Todo indivíduo é diferente. Devemos respeitar e tratar a todos da mesma forma" (BOLER; ZEMBYLAS, 2003, p. 109, grifos dos autores). A celebração da diferença que se encerra em si mesma, ou seja, que parte do princípio de que todos devem ser tratados igualmente, é bastante comum nas sociedades neoliberais. Neste modelo, as relações de poder que subjugam a diferença não são levadas em conta, e temas como raça, gênero e sexualidade são evitados para que se não firam os valores alheios. Ironicamente, dizem os autores, os valores da cultura dominante não são vistos como ameaça aos valores alheios, e, portanto, a diferença reside apenas nos indivíduos já destituídos de poder e, por isso mesmo, são aqueles a se calarem diante do discurso regulador da tolerância. Esse modelo reforça as injustiças sociais no sentido em que ignora as desigualdades e pressupõe que todos se situam em posição de igualdade nas relações sociais.

A segunda concepção, chamada de modelo da negação ou da semelhança/uniformidade, emerge de discursos como "Somos todos iguais embaixo da pele. Por que temos que prestar tanta atenção à diferença?” (p. 110, grifos dos autores). Esse apagamento da diferença, 
segundo os autores, está estreitamente comprometido à assimilação cultural. Somente a cultura dominante tem o privilégio de decidir quando e quais diferenças são importantes. Essa abordagem encobre "as formas pelas quais o poder molda e procura apagar a diferença" (BOLER; ZEMBYLAS, 2003, p. 110)

A terceira concepção, chamada pelos autores de modelo biológico ou de resposta natural, revela discursos como "Algumas diferenças são inatas. Alguns medos da diferença são inatos. O medo da diferença é uma resposta natural" (BOLER; ZEMBYLAS, 2003, p. 110, grifos dos autores). Essa abordagem, encorajada pelo individualismo liberal, tenta justificar a xenofobia, ao descrever o medo das diferenças como "uma emoção natural, um medo que deve ser entendido como uma característica fundamental do ser humano" (p. 110). Essa explicação meramente biológica justifica a opressão de um grupo sobre o outro, e autoriza a discriminação e o preconceito à diferença.

As três formas de abordar a diferença apresentadas acima desvelam uma questão extremamente grave na maneira com a qual (muitos de nós) nos relacionamos com a diferença: uma forte tendência a nos isentarmos de responsabilidade na produção e na perpetuação das desigualdades e no silenciamento das diferenças. Como já afirmamos anteriormente, somos sujeitos sócio-históricos em constante formação/construção, e produzimos e negociamos sentidos no cotidiano das práticas sociais. Ou seja, a nossa historicidade não faz de nós meros fantoches das relações sociais; ao contrário, como esclarece Bakhtin (2006), somos agentes responsáveis e responsivos diante do/no diálogo social, e, dessa forma, temos um compromisso ético com o efeito das nossas construções no mundo social e na vida das outras pessoas.

A fim de encorajar o engajamento crítico e emocional diante da diferença, Boler e Zembylas (2003) propõem uma 'pedagogia do desconforto' que "reconhece e problematiza as dimensões emocionais profundamente enraizadas que moldam os hábitos cotidianos, as rotinas e a cumplicidade inconsciente com a hegemonia" (BOLER; ZEMBYLAS, 2003, p. 108). Segundo os autores, ao examinarmos mais detidamente nossas reações e respostas emocionais à diferença, começamos a identificar formas aparentemente invisíveis pelas quais nos aliamos à ideologia dominante.

O desconforto deve-se à questão de que ninguém quer ser confrontado com o fato de que "as escolhas que acreditam ter feito não são, de fato, resultado do livre-arbítrio, mas sim determinadas por poderosas forças ideológicas" (BOLER; ZEMBYLAS, 2003, p. 111). Contudo, a perpetuação das injustiças se sustenta principalmente na forma com que os indivíduos internalizam os valores dominantes que passam a moldar a própria maneira desses indivíduos se relacionarem entre si. E, ao pressionar um indivíduo contra o outro, a lógica 
dominante destrói o espaço entre eles (ARENDT, 1958), ou seja, impede que o diálogo e a negociação possibilitem a integração da diferença na construção de outros valores e identidades culturais.

Se afirmamos anteriormente que percebemos cultura como sendo socialmente construída, entendemos ser prioridade combater as lógicas binárias (certo e errado, normal e anômalo, culto e ignorante etc.) em prol de construções que acolham a diferença, a pluralidade, os atravessamentos, e que multipliquem as possibilidades de ação em prol de um mundo mais justo e mais diverso. A diferença nos permite "produzir novas narrativas que corroem os preconceitos que tantas vezes atribuímos aos outros, e, não raro, a nós mesmos" (BOLER; ZEMBYLAS, 2003, p. 124).

O esforço e o risco emocional a que nos expomos quando nos colocamos vulneráveis à diferença são recompensados com resultados que vão muito além da emersão de novas narrativas, e que se revelam em forma de autoconhecimento, esperança, senso de responsabilidade e engajamento com a mudança, promovendo um "novo sentido de interconexão com os outros" (BOLER; ZEMBYLAS, 2003, p. 124) e ressignificando nossos papéis na construção de novos futuros possíveis, modificando o mundo enquanto nos modificamos com ele.

\section{A pluriversalidade como opção universal}

Conforme observamos em nosso exercício de desterritorialização do pensamento, nossas interpretações estão constantemente condicionadas às relações de poder que regulam as nossas formas de ser e de agir no mundo. Como afirma Ferraz (2018, p. 105), nossos olhares muitas vezes se apresentam "fortemente marcados por valores socioculturais e ideológicos unilaterais e estáticos". E, se os processos de dominação ideológica se constituem e se reproduzem no campo do discurso, podemos dizer que é por meio da língua/linguagem que negociamos saberes e visões de mundo. Por essa razão, refutamos a ideia de "neutralidade" da língua/linguagem e defendemos o engajamento consciente com múltiplos sistemas de conhecimento, para que não estejamos confinados a uma perspectiva única e para que possamos enxergar novas políticas de significação não coercitivas.

Dessa forma, cientes de que todo e qualquer fenômeno pode e deve ser analisado em seus aspectos sociais, históricos, culturais, políticos e ideológicos, sugerimos um olhar para a linguagem (e para o conhecimento) que se aproxime das expansões interpretativas ou expansões de perspectivas propostas por Monte Mór (2018), que constituem um exercício de desnaturalização ou desconstrução do que a autora chama de raciocínios disciplinadores (e.g. 
ordem natural, valores institucionais, linearidade/completude, hierarquia, centralidade, binarismos, etc.). Conforme nos alertam Morgan e Mattos (2018, p. 214), é preciso "desafiar práticas existentes e hábitos de pensamento".

Assim, ao questionar a supremacia de princípios e valores que se pretendem universais, promovemos um espaço privilegiado de pensamento, em que o conhecimento dominante (totalitário e ilusoriamente universal) é compreendido em sua localidade e relatividade, pois que todas as formas de conhecimento residem na parcialidade, na relatividade e na incompletude (MIGNOLO, 2018). Tal relativização do conhecimento nos possibilita o engajamento com outras interpretações/visões de mundo/formas de saber diferentes daquelas hegemônicas, generalizantes, homogeneizantes e naturalizadas.

Nesse sentido, um grupo de autores/intelectuais latino-americanos (e.g. o sociólogo peruano Aníbal Quijano, o semiólogo e teórico cultural argentino Walter Mignolo, o sociólogo porto-riquenho Ramón Grosfoguel, a linguista norte-americana radicada no Equador Catherine Walsh, dentre outros) vem propondo um exercício de questionamento da geopolítica do conhecimento que sustenta a lógica da modernidade. Para esses intelectuais, a modernidade não corresponde a um período histórico, mas a uma invenção da hegemonia europeia a partir do seu contato com a América. A modernidade, nessa acepção, envolve uma gama de narrativas de autopromoção, construídas no imaginário europeu, a partir de atores, instituições e línguas que beneficiaram e beneficiam aqueles que as imaginaram e que as sustentam por meio do conhecimento, da guerra e do poder econômico (MIGNOLO, 2018).

As macronarrativas da modernidade se autopromovem por meio do discurso de progresso e desenvolvimento. No entanto, tal discurso universalista esconde, de forma engenhosa, o lado obscuro da modernidade, a violência colonial, impressa naqueles que foram inferiorizados, subjugados e que tiveram sua razão e suas experiências negadas pela retórica da modernidade. Assim, a colonialidade, enquanto elemento constitutivo da modernidade e do seu específico padrão de poder (QUIJANO, 2009), diferenciou a população do mundo em inferiores e superiores, irracionais e racionais, primitivos e civilizados, tradicionais e modernos .

A modernidade eurocêntrica, portanto, enquanto narrativa hegemônica, suprimiu outras narrativas (e outras modernidades) que agora, a partir das margens criadas na estruturação do mundo moderno/colonial, reclamam sua coexistência por meio do desprendimento da história única e do senso comum, trazendo à tona outras formas de pensar, de ser, de sentir e de agir no mundo (o que implica outras formas de interpretar a cultura). Esse desprendimento da retórica da modernidade é a essência do chamado pensamento decolonial, que não se pretende universal (pois que seria mera inversão do privilégio epistêmico), mas busca desvincular-se das epistemes 
e paradigmas modernos. "Não que as epistemes e paradigmas sejam estranhos ao pensamento decolonial. Eles não poderiam ser; mas eles deixaram de ser a referência de legitimidade epistêmica" (MIGNOLO, 2014, p. 26). A decolonialidade, dessarte, não resulta da combinação das epistemologias e dos paradigmas existentes; ao contrário, consiste em desprender-se deles.

No entanto, a opção decolonial não se coloca como forma de resistência, pois como afirma Mignolo (2014, p. 44), "resistir significa que as regras do jogo são controladas por alguém a quem resistimos". A decolonialidade permite que outros saberes e outros sujeitos emergentes da diferença colonial enunciem e protagonizem suas próprias histórias e, a partir da diferença, possam imaginar e construir uma práxis de vida que contemple suas próprias convicções e necessidades.

No mesmo sentido, Walsh $(2014$, p. 53) propõe a interculturalidade como lugar de enunciação da diferença colonial, como um "instrumento propulsor tanto de intervenção e transformação como de criação de diferentes condições de relacionamento". Para a autora, a interculturalidade não se assemelha à ideia de multiculturalismo. Este último, que universaliza a noção de diversidade, visa a administrá-la, tornando-a funcional à expansão do neoliberalismo; em outras palavras, pretende assimilar e interromper a diferença. A interculturalidade opõe-se à ideia da simples inclusão da diferença às estruturas já estabelecidas; ela se faz propositiva, pretende reconceitualizar e refundar as estruturas, para que delas participem, de forma equitativa, "lógicas, práticas e modos culturais diversos de pensar, agir e viver" (WALSH, 2012, p. 119).

Logo, a interculturalidade, enquanto prática decolonial, possibilita uma reconfiguração social a partir da experiência vivida da decolonialidade, "dando assim uma volta à geopolítica dominante do conhecimento que tem tido seu centro no norte global" (WALSH, 2005, p. 25).

Ao opor-se ao pensamento único, a decolonialidade (bem como a interculturalidade) defende a pluriversalidade como única opção universal, a fim de possibilitar a coexistência e a cooperação de múltiplos e diversos projetos econômicos, políticos, culturais, sociais e subjetivos "outros" (MIGNOLO, 2007) que transgridam a lógica moderna-ocidental e a hegemonia geopolítica do conhecimento.

Acreditamos que as reflexões levantadas nessa seção contribuem para a (des)construção de nossas interpretações acerca de cultura. Percebemos que as relações culturais não podem ser analisadas fora do contexto das relações de poder que as regulam e as constituem. Assim, os projetos de inclusão da diferença em pouco contribuem se não há um movimento de transformação das estruturas que controlam as relações. Além de colocar os diferentes conhecimentos em diálogo, faz-se necessário adotar um posicionamento crítico diante de tais 
conhecimentos, para que se possa almejar a reconfiguração das relações e a simultaneidade das diferentes formas de existência - a pluriversalidade.

\section{Conclusão: Cultura no plural}

Ao nos entendermos como indivíduos atravessados por identidades diversas e, ao refletirmos acerca de nossos hábitos, comportamentos, ações e emoções, conseguimos perceber (algumas das) forças antagônicas (ou não) que nos permeiam. E, quais sejam os valores e princípios que nos orientam, somos contraditórios e somos muitos antes mesmo de adentrarmos a interação dialógica uns com os outros.

Portanto, entendemos que essa luta entre forças divergentes converge para o entendimento de cultura como espaço semiótico sempre dialógico e aberto à transformação. Cultura, pois, nos deslocamentos, rupturas e articulações diversas. Cultura na não-ordem, nas contradições nossas de cada dia. Cultura nas identidades múltiplas e híbridas, nos aspectos gerais e particulares. Cultura no desconforto, no desprendimento. Cultura nas fronteiras (e para além delas), nos atravessamentos, no entre-lugar. Cultura na diferença. Cultura no plural, na coexistência, na pluriversalidade. Cultura quando reagimos, nos engajamos e respondemos a tudo e a todos que nos rodeiam, num incessante movimento que recusa o ponto final.

\section{Referências}

ANDREOTTI, V.; MENEZES DE SOUZA, L. M. Translating theory into practice and walking minefields: Lessons from the project 'Through Other Eyes'. International Journal of Development Education and Global Learning, (1). London: UCL, 2008.

ARENDT, H. The origins of totalitarianism. New York, NY: Meridian Books, 1958.

ARENDT, H. The human condition. Chicago: The University of Chicago Press, $2^{\text {nd }}$ edition, 1998.

BAKHTIN, M. Questões de literatura e de estética: a teoria do romance. São Paulo: Hucitec, 2002.

BAKHTIN, M. Marxismo e filosofia da linguagem. São Paulo: Hucitec, 2006.

BHABHA, H. K. O local da cultura. Belo Horizonte: Editora UFMG, 1998.

BOLER, M.; ZEMBYLAS, M. Discomforting truths: The emotional terrain of understanding differences. Pedagogies of difference: Rethinking education for social justice, 2003, p. 110136.

CANAGARAJAH, S. Negotiating diversity in English Language Teaching: A tragedy in four acts. ELTWO: NUS CELC 5th Symposium Proceedings, 2016. 
CORNWALL, A. Making spaces, changing places: situating participation in development. IDS, Working Paper 170. Sussex: Institute of Development Studies, October 2002.

DEBARBIEUX, B. Hannah Arendt's spatial thinking: an introduction. Territory, Politics, Governance, 5:4, 2017, p. 351-367.

FERRAZ, D. M. Educação linguística e transdisciplinaridade. In: PESSOA, R. R.; SILVESTRE, V. P. V.; MONTE MÓR, W. (Orgs.). Perspectivas críticas de educação linguística no Brasil: trajetórias e práticas de professoras(es) universitárias(os) de inglês. 1. ed. São Paulo: Pá de Palavra, 2018.

GARCIA-CANCLINI, N. G. Culturas híbridas: estratégias para entrar e sair da modernidade. São Paulo: UNESP, 2011.

HALL, S. A identidade cultural na pós-modernidade. Rio de Janeiro: DP\&A Editora, 11 Edição, 2006.

HUNTINGTON, S. Political development and political decay. World Politics, vol. 17, n.3, 1965 , p. 386-430.

KUBOTA, R. Critical multiculturalism and second language education. In: Norton, B. \& K. Toohey. (Eds.). Critical pedagogies and language learning. Cambridge: Cambridge University Press, 2004.

MACHADO, I. Espaço semiótico em diálogos e fronteiras. CASA: Cadernos de Semiótica Aplicada, v.13, n.1, 2015, p. 87-119.

MAHER, T. M. Do casulo ao movimento: A suspensão das certezas na educação bilíngue e intercultural. In: Cavalcanti, M. C.; Bortoni-Ricardo, S. M. (orgs.). Transculturalidade, linguagem e educação. Campinas, SP: Mercado de Letras, 2007, p. 67-94.

MIGNOLO, W. El pensamento decolonial: desprendimiento y apertura: un manifiesto. In: CASTRO-GÓMEZ, S.; GOSFOGUEL, R. (Orgs.). El giro decolonial: reflexiones para una diversidad epistémica más allá del capitalismo global. Bogotá: Siglo del Hombre Editores; Universidad Central, Instituto de Estudios Sociales Contemporáneos y Pontificia Universidad Javeriana, Instituto Pensar, 2007, p. 25-46.

MIGNOLO, W. Retos decoloniales, hoy. In: BORSANI, M. E.; QUINTERO, P (Orgs.). Los desafíos decoloniales de nuestros días: pensar em colectivo. Neuquén: Educo, 2014, p. 23-46.

MIGNOLO, W. Eurocentrism and Coloniality: The Question of Totality of Knowledge. In: MIGNOLO, W.; WALSH, C (Orgs.). On Decoloniality: Concepts, Analytics, Praxis. Durham: Duke University Press, 2018, p. 194-210.

MONTE MÓR, W. Sobre rupturas e expansão na visão de mundo: seguindo as pegadas e os rastros da formação crítica. In: PESSOA, R. R.; SILVESTRE, V. P. V.; MONTE MÓR, W. (Orgs.). Perspectivas críticas de educação linguística no Brasil: trajetórias e práticas de professoras(es) universitárias(os) de inglês. 1. ed. São Paulo: Pá de Palavra, 2018.

MORGAN, B.; MATTOS, A. Theories and practices in critical language teaching: A dialogic introduction. RBLA, vol. 18, n.2, 2018, p. 213-226. 
QUIJANO, A. Colonialidade do poder e classificação social. In: SANTOS, B. S.; MENESES, M. P. Epistemologias do Sul. Coimbra: Almedina, 2009, p. 73-117.

SANTIAGO, Silviano. Uma literatura nos trópicos: ensaios sobre dependência cultural. Rio de Janeiro: Rocco, $2^{\circ}$ ed., 2000 (primeira publicação em 1978).

WALSH, C. (Re)pensamiento crítico y (de)colonialidad. In: WALSH, Catherine. (Org.). Pensamiento crítico y matriz (de)colonial. Reflexiones latinoamericanas. Quito: Ediciones Abya-yala, 2005, p. 13-35.

WALSH, C. Interculturalidad crítica y (de)colonialidad. Ensayos desde Abya Yala. Quito: Abya/Yala Instituto Científico de Culturas Indígenas, 2012.

WALSH, C. Decolonialidad, Interculturalidad, Vida desde el Abya Yala-Andino: Notas pedagógicas y senti-pensantes. In: BORSANI, M. E.; QUINTERO, P. (Orgs.). Los desafíos decoloniales de nuestros días: pensar em colectivo. Neuquén: Educo, 2014, p. 47-78. 